Article

\title{
Condensation of Model Lipid Films by Cholesterol: Specific Ion Effects
}

\author{
Alberto Martín-Molina ${ }^{1,2}{ }^{\circledR}$, Teresa Del Castillo-Santaella ${ }^{1}\left(\mathbb{D}\right.$, Yan Yang ${ }^{1}(\mathbb{D}$ and \\ Julia Maldonado-Valderrama ${ }^{1,3, *}$ \\ 1 Departamento de Física Aplicada, University of Granada, Campus de Fuentenueva sn, 18071 Granada, Spain \\ 2 Instituto Carlos I de Física Teórica y Computacional, University of Granada, 18071 Granada, Spain \\ 3 Excellence Research Unit “Modelling Nature" (MNat), University of Granada, 18071 Granada, Spain \\ * Correspondence: julia@ugr.es; Tel.: +34-958-241000-20387
}

Received: 1 July 2019; Accepted: 25 July 2019; Published: 27 July 2019

\begin{abstract}
The condensing effect and the ability of cholesterol (CHOL) to induce ordering in lipid films is a question of relevance in biological membranes such as the milk fat globule membrane (MFGM) in which the amount of CHOL influences the phase separation and mechanical resistance to rupture of coexisting phases relevant to emulsified food systems. Here, we study the effect of different salts $\left(\mathrm{NaCl}, \mathrm{CaCl}_{2}, \mathrm{MgCl}_{2}, \mathrm{LaCl}_{3}\right.$ ) on monolayers made of a model mixture of lipids (DPPC:DPPS 4:1) and CHOL. To this end, we apply Langmuir Film Balance to report a combined analysis of surface pressure-area $(\pi-A)$ and surface potential-area $(\Delta V-A)$ isotherms along with Micro-Brewster Angle Microscopy (Micro-BAM) images of the monolayers in the presence of the different electrolytes. We show that the condensation of lipid by $\mathrm{CHOL}$ depends strongly on the nature of the ions by altering the shape and features of the $\pi-A$ isotherms. $\Delta V-A$ isotherms provide further detail on the ion specific interactions with CHOL. Our results show that the condensation of lipids in the presence of $\mathrm{CHOL}$ depends on the combined action of ions and $\mathrm{CHOL}$, which can alter the physical state of the monolayer.
\end{abstract}

Keywords: lipid; cholesterol; ions; monolayer; surface pressure; elasticity; BAM; surface potential

\section{Introduction}

Cholesterol (CHOL) is an important component in cell membranes of most vertebrates, being an essential component of brain and nerve cells and of bile, which helps the body absorb fats and fat-soluble vitamins [1]. CHOL is usually synthesized in animals and smaller quantity of CHOL can be generated in plants. Although the body can produce all the CHOL that it needs, it also obtains $\mathrm{CHOL}$ through foods. CHOL participates in several membrane trafficking and transmembrane signaling processes [2,3] and plays an important role in the cellular processes such as endocytosis and exocytosis [4]. Beyond the field of fundamental biology, CHOL is an important element in the development of new biomaterials; as a helper lipid in liposomes developed for drug delivery $[5,6]$ or in lipoplexes for gene therapy $[7,8]$.

The fundamental functions of the $\mathrm{CHOL}$ include cellular processes by interacting with other lipids and proteins in the membrane. As a consequence, $\mathrm{CHOL}$ has been extensively studied since the late 18th century until present [1-4,9-13]. In contrast to phospholipids (formed by a larger hydrophilic head and a longer, flexible hydrocarbon tails), CHOL presents a peculiar structure. Concretely, CHOL contains a short, thermally flexible hydrocarbon tail with a rigid hydrophobic structure containing four hydrocarbon rings, which is attached to a small polar headgroup consisting of only one hydroxyl group. Due to this chemical structure it does not form bilayer structures. Instead, it interacts strongly with other lipids in such a way that it always fits in between two lipids in a bilayer, altering the mechanical 
strength of the membrane and inducing a non-ideal behavior in mixed systems (known as condensing effect) $[9,13]$. This non-ideal behavior was firstly observed by Leathes in 1925 who studied mixtures of CHOL and egg lecithin monolayers [14]. Therein, it was proved that the average area per molecule in mixtures was much lower than what would be expected from the individual components. Since then, the condensing effect and the ability of $\mathrm{CHOL}$ to induce ordering within the hydrocarbon chain of many lipid films, has been extensively characterized using Langmuir films [15-29]. For instance, this technique has been used to bring new insight into the functional role of CHOL in milk polar lipids, used in the preparation of dairy emulsions, e.g., infant milk formulas. In particular, the role played by $\mathrm{CHOL}$ in the organization of biological membranes surrounding lipid droplets in milk, called the milk fat globule membrane (MFGM), has been recently investigated [30-33]. Accordingly, $\mathrm{CHOL}$ concentration facilitates the phase separation and reduces the mechanical resistance to rupture of coexisting phases in bilayer models of the MFGM. CHOL strongly affects the organization of the MFGM lipid monolayers by condensing the polar lipid molecules, decreasing the difference in height between domains on non-condensed phases and promoting the formation of numerous small domains in the condensed phase.

In addition to the above mentioned studies of Langmuir Films, Atomic Force Microscopy (AFM) and Brewster Angle Microscopy (BAM) are complementary techniques that are vastly employed in the studies of lipid-CHOL interactions $[13,24,25,28,34]$. Although these techniques provide a direct correlation between the topography and force mapping, the exact mechanism of the interaction of $\mathrm{CHOL}$ with the individual lipids is not yet fully understood. For instance, Adhyapak and co-workers have recently pointed out some of the questions which remain unsolved: (i) How does CHOL exactly affect the mechanical stability of lipids, (ii) what is the nature of the binding of CHOL with different types of lipids, (iii) what happens in the limits of low and excess CHOL conditions, and finally, (iv) how does the self-organized structure of lipids break in the presence of CHOL [13]? Notwithstanding the aforementioned, what is known is that the presence of CHOL increases the ordering (cohesion, packing) of neighboring lipids [2] but simultaneously contributes to increase the fluidity of the bilayer (lateral diffusion) [35]. However, this double character of systems containing CHOL can be modulated by the presence of ions in the liquid subphase. For example, Korchowiec and co-workers demonstrated that the presence of $\mathrm{Na}^{+}$and $\mathrm{Ca}^{2+}$ increased the monolayer condensation, stability, and packing density in 1,2-dipalmitoyl-sn-glycero-3-phosphoethanolamine (DPPE) and CHOL mixed films (especially for the case of the $\mathrm{Ca}^{2+}$ ) [17]. Likewise, Wydro and co-workers studied monolayers containing CHOL and saturated phosphatidylethanolamine (PE) and phosphatidylserine (PS) and revealed that interactions between lipids were enhanced in the presence of $\mathrm{Na}^{+}$[36]. Accordingly, small changes in the ionic environment induce significant alterations to the bilayer structure. Moreover, in both monolayers and bilayers, the interaction of lipids with ions depends on the ion nature, on the lipid headgroups, and also on the degree of unsaturation of the lipid hydrocarbon chain [37-44]. In this sense, we recently studied the effect of different salts ( $\mathrm{NaI}, \mathrm{NaCl}, \mathrm{CaCl}_{2}$, and $\mathrm{MgCl}_{2}$ ) on monolayers made of $\mathrm{CHOL}$ molecules, both experimentally and theoretically [23]. In particular, we performed experiments of surface area $(A)$ vs. lateral pressure $(\pi)$ isotherms measured by a Langmuir Film Balance together with molecular dynamics (MD) all-atomic simulations. Therein, we found that surface isotherms depend on the nature of the ions by altering the shape and features of the isotherm. Concretely, experimental $\pi-A$ isotherms were qualitatively similar for $\mathrm{NaCl}$ and $\mathrm{CaCl}_{2}$, but differ substantially from the shapes observed for $\mathrm{MgCl}_{2}$ and NaI. The fact that the isotherms display differences for each electrolyte makes it difficult to propose a series or ranking of the effect of the ions, ranging from those having more impact to less impact on the isotherms, contrary to what is usually done in specific ionic effects (the so-called Hofmeister series, popular in colloidal science [45]). In this research, we also measured the surface potential $(\Delta V)$, which provides additional information on the orientation of the film constituents. In line with Del Castillo-Santaella et al.'s experiments [23], MD simulations performed therein also revealed clear evidences of specific ionic effects and provided molecular level details on ion specific interactions with monolayers of pure CHOL. 
Accordingly, in this research we extended previous results to explore the interaction of CHOL with a mixture of lipids in the presence of different ions in the subphase and used a complete surface characterization based on surface pressure, surface potential, and Brewster Angle Microscopy. The mixture of lipids chosen is a model system, representative of the cell membrane; 1,2-dipalmitoyl-snglycero-3-phosphocholine (DPPC), 1,2-dipalmitoyl-sn-glycero-3-phospho-L-serine (DPPS). The amount of CHOL varies from $0,30 \%, 70 \%$, and $100 \%$, and the salts used are $\mathrm{NaCl}, \mathrm{CaCl}_{2}, \mathrm{MgCl}_{2}$, and $\mathrm{LaCl}_{3}$. The objective of this research is to investigate the condensation of model lipids by CHOL and how specific interactions with ions can alter this interaction in order to shed light on the biological functions of this interface.

\section{Materials and Methods}

\subsection{Materials}

1,2-dipalmitoyl-sn-glycero-3-phosphocholine, 16:0 phosphatidylcholine (PC), 850355 (DPPC) and 1,2-dipalmitoyl-sn-glycero-3-phospho-L-serine (sodium salt), 16:0 phosphatidylserine (PS), 840037 (DPPS), were purchased from Avanti Polar Lipids (Delfzyl, The Netherlands), ( $\geq 99 \%$ purity) and used as received. Cholesterol, C8667 (CHOL) was purchased from Sigma-Aldrich (Saint Louis, MO, USA), ( $\geq 99 \%$ purity) and used as received. Spreading solutions were prepared in chloroform/methanol 4:1 $(v / v)$ mixture (HPLC grade, $\geq 99 \%$, Sigma-Aldrich).

Mixtures of lipids were prepared in the following ratios: DPPC:DPPS:COL (0.8:0.2:0), (0.56:0.14:0.3), (0.24:0.06:0.7), and (0:0:1) (mol/mol) by dissolving the phospholipids in chloroform/methanol 4:1 $(\mathrm{v} / \mathrm{v})$ under ambient conditions. Hence, the CHOL was used at different proportions $(0,30 \%, 70 \%$, and $100 \%$ ) from the total amount of lipids in a solution of final concentration $0.5 \mathrm{mg} \mathrm{mL}^{-1}$.

Hence, we analyzed the impact of CHOL on a mixture of DPPC:DPPS 4:1 as detailed in Table 1.

Table 1. Composition of the lipid mixtures (DPPC:DPPS:CHOL).

\begin{tabular}{ccccc}
\hline Sample & DPPC & DPPS & CHOL & DPPC:DPPS:CHOL \\
\hline DPPC:DPPS 4:1 & 0.8 & 0.2 & 0 & $0.8: 0.2: 0$ \\
DPPC:DPPS:CHOL30 & 0.56 & 0.14 & 0.3 & $0.56: 0.14: 0.3$ \\
DPPC:DPPS:CHOL70 & 0.24 & 0.06 & 0.7 & $0.24: 0.06: 0.7$ \\
CHOL & 0 & 0 & 1 & $0: 0: 1$ \\
\hline
\end{tabular}

Electrolyte solutions were all used as received: $\mathrm{CaCl}_{2}$ solution (Fluka, Hampton, $\mathrm{NH}, \mathrm{USA}, 21114$ ), $\mathrm{MgCl}_{2}$ solution (Fluka, 65020), $\mathrm{NaCl}$ (Sharlau, Barcelona, Spain, S02241000), and $\mathrm{LaCl}_{3}$ (Sigma-Aldrich, 31820). These were diluted in ultrapure water in order to maintain a constant ionic strength of $I=15$ $\mathrm{mM}: 15 \mathrm{mM} \mathrm{NaCl}, 5 \mathrm{mM} \mathrm{CaCl}_{2}$, or $5 \mathrm{mM} \mathrm{MgCl}_{2}$ and $2.5 \mathrm{mM} \mathrm{LaCl}_{3}$.

Ultrapure water, cleaned using a Milli-Q water purification system $(18.2 \mathrm{M} \Omega \mathrm{cm}$, Merck KGaA, Darmstadt, Germany), was used for the preparation of buffer solutions. All glassware was washed with 10\% Micro-90 cleaning solution and exhaustively rinsed with tap water, isopropanol, deionized water, and ultrapure water in this sequence. All other chemical used were of analytical grades and used as received.

\subsection{Experimental Methods}

\subsubsection{Langmuir Film Balance}

Lipid monolayers made of mixtures of lipids DPPC:DPPS:CHOL (Table 1) were formed at the air-water interface in a Langmuir Film Balance equipped with paper Wilhelmy plate surface pressure measuring system (KSV). The trough was thoroughly cleaned before every measurement with the following sequence: $10 \%$ Micro- $90^{\circledR}$ (Burglinton, NJ, USA) cleaning solution, tap water, isopropanol, distilled water, and ultrapure water. The trough was filled with the adequate subphase $\left(\mathrm{NaCl}, \mathrm{CaCl}_{2}\right.$, 
$\mathrm{MgCl}_{2}$, and $\mathrm{LaCl}_{3}, I=15 \mathrm{mM}$ ). The absence of surface active impurities was tested within the whole compression range before every experiment obtaining values of surface pressure $\pi<0.2 \mathrm{mN} \mathrm{m}^{-1}$. After equilibration of the subphase, $50 \mu \mathrm{L}$ of each lipid mixture (Table 1) were carefully spread on the subphase using a microsyringe (Hamilton ${ }^{\circledR}$, Teknocroma, Barcelona, Spain). After $20 \mathrm{~min}$ to assure the evaporation of the solvent, the surface pressure-area $(\pi-A)$ isotherm was recorded at a constant rate of $5 \mathrm{~mm} \mathrm{~min}{ }^{-1}$. The reproducibility of the $\pi-A$ isotherms spread on different subphases was tested by measuring in triplicate for independent samples and obtaining standard deviation $<5 \%$. Final values are expressed as mean values of replicates \pm standard deviations according to statistical analysis tools. The Langmuir film balance lies on an antivibrational table and is covered with a transparent Plexiglas case in order to avoid perturbation of the air-water interface by air stream and/or dust deposition. The temperature of the subphase was controlled by a circulation water system thermostat at $23.0 \pm 0.1^{\circ} \mathrm{C}$.

The surface Gibbs elasticity of the monolayer is calculated directly from the $\pi-A$ isotherms using

$$
\varepsilon_{0}=-A\left(\frac{\mathrm{d} \pi}{\mathrm{d} A}\right)_{T}
$$

The isotherms are plotted vs. the mean molecular area (MMA), the lift off area corresponds to the $\pi$ - $A$ plot extrapolation to 0 in the liquid-expanded (LE) regime, the limiting molecular area (LMA) corresponds to the $\pi$ - $A$ plot extrapolation to 0 in the liquid-condensed (LC) regime and the collapse pressure $\left(\pi_{\text {coll }}\right)$ is the $\pi$ at the highest compression state of the monolayer before collapse.

\subsubsection{Brewster Angle Microscope}

The morphology of the lipid films at the air/water surface was observed by Brewster Angle Microscopy using a KSV NIMA MicroBAM (Biolin Scientific, Gothenburg, Sweden) mounted on the Langmuir Trough. The MicroBAM is equipped with a $50 \mathrm{~mW}$ laser emitting p-polarized light of $659 \mathrm{~nm}$ wavelengths and the spatial resolution is $12 \mu \mathrm{m}$. The dimensions of each image are $3.6 \mathrm{~mm} \times 4.0 \mathrm{~mm}$. The technique is sensitive to the density and thickness of the film on the air-water surface. At the Brewster angle, no reflected signal is detected on the bare air-water surface. The reflected index changes when a monolayer is formed on the surface and so the light is reflected and detected by the camera [28]. MicroBAM images were taken while recording the $\pi$ - $A$ isotherms of DPPC:DPPS:CHOL (Table 1) spread on different subphases ( $\mathrm{NaCl}, \mathrm{CaCl}_{2}, \mathrm{MgCl}_{2}$, and $\mathrm{LaCl}_{3}, I=15 \mathrm{mM}$ ). The images shown are representative of at least three independent experiments using three samples prepared separately.

\subsubsection{Surface Potential}

Surface potential-surface area $(\Delta V-A)$ isotherms were measured simultaneously to the $\pi-A$ isotherms in the Langmuir trough with the KSV NIMA Surface Potential Sensor. This accessory measures the potential difference above and below the film and is sensitive to the sum of all the individual dipole moments. The changes in surface potential are measured by detecting the potential difference between the vibrating plate which is placed above the monolayer and the counter electrode which is immersed in the subphase below the monolayer [46]. $\Delta V-A$ isotherms were recorded similarly for each lipid mixture DPPC:DPPS:CHOL (Table 1) spread on different subphases $\left(\mathrm{NaCl} \mathrm{CaCl}_{2}, \mathrm{MgCl}_{2}\right.$, and $\mathrm{LaCl}_{3}, I=15 \mathrm{mM}$ ) upon symmetric uniaxial compression of the barriers.

\section{Results}

Surface pressure-area $(\pi-A)$ isotherm of a lipid monolayer provides a fundamental characterization of the properties of the interfacial film including information on the lateral interactions and the surface Gibbs elasticity $\left(\varepsilon_{0}\right)$ of the film. Meanwhile, the surface potential-area $(\Delta V-A)$ isotherms provide additional information on the orientation of the film constituents. Finally, BAM enables visualization of the different conformational regimes of the lipids in the monolayer by evaluating the appearance of 
uniform textures or appearance of bright/dark regions. Bright regions correspond to condensed phase and dark regions correspond to expanded phases.

\section{1. $\pi$-A Isotherms}

Lipid monolayers undergo different molecular regimes as they are compressed. Gaseous films display a $\pi$ close to 0 . LE films are characterized by a gentle rise of the $\pi$ and a low $\varepsilon_{0}$. In LE films, the $\pi-A$ plot extrapolates at $\pi=0$ to an area called lift off area. LC films are characterized by a steep rise of the $\pi$ as molecules begin to be close-packed and LC films show higher $\varepsilon_{0}$. The transition between LE and LC can display a coexistence region characterized by a planar region of $\pi$ between regimes (LE-LC). In LC films the $\pi-A$ plot extrapolates to zero $\pi$ at an area called limiting molecular area (LMA), near the molecular cross section. On further compression the film collapses in a three-dimensional state at the collapse pressure $\pi_{\text {coll }}$.

Figure 1 shows the $\pi-A$ isotherms obtained at the air-water interface for the different DPPC:DPPS:CHOL mixtures studied. These were spread on subphases containing different electrolytes $\left(\mathrm{NaCl}, \mathrm{CaCl}_{2}, \mathrm{MgCl}_{2}\right.$, and $\left.\mathrm{LaCl}_{3}\right)$ at concentrations to match the same ionic strength of $15 \mathrm{mM}$; in this way we can focus on the specific interactions in each system. Experiments were also carried on water subphase obtaining no significant differences with the monovalent electrolyte (results not shown). In general, Figure 1 shows how the addition of $\mathrm{CHOL}$ in the mixture displaces the isotherms to lower MMAs. This is indicative of the condensation of the lipid monolayer by CHOL. However, this condensation appears to be dependent on the nature of the ions in the subphase. Tables 2-5 display the values of the LMAs, $\pi_{\mathrm{coll}}$, and $\varepsilon_{0}$ of the monolayers for each of the electrolyte used in the subphase. We shall analyze the effect of each of the ions on the $\pi-A$ isotherms of DPPC:DPPS:CHOL, separately.
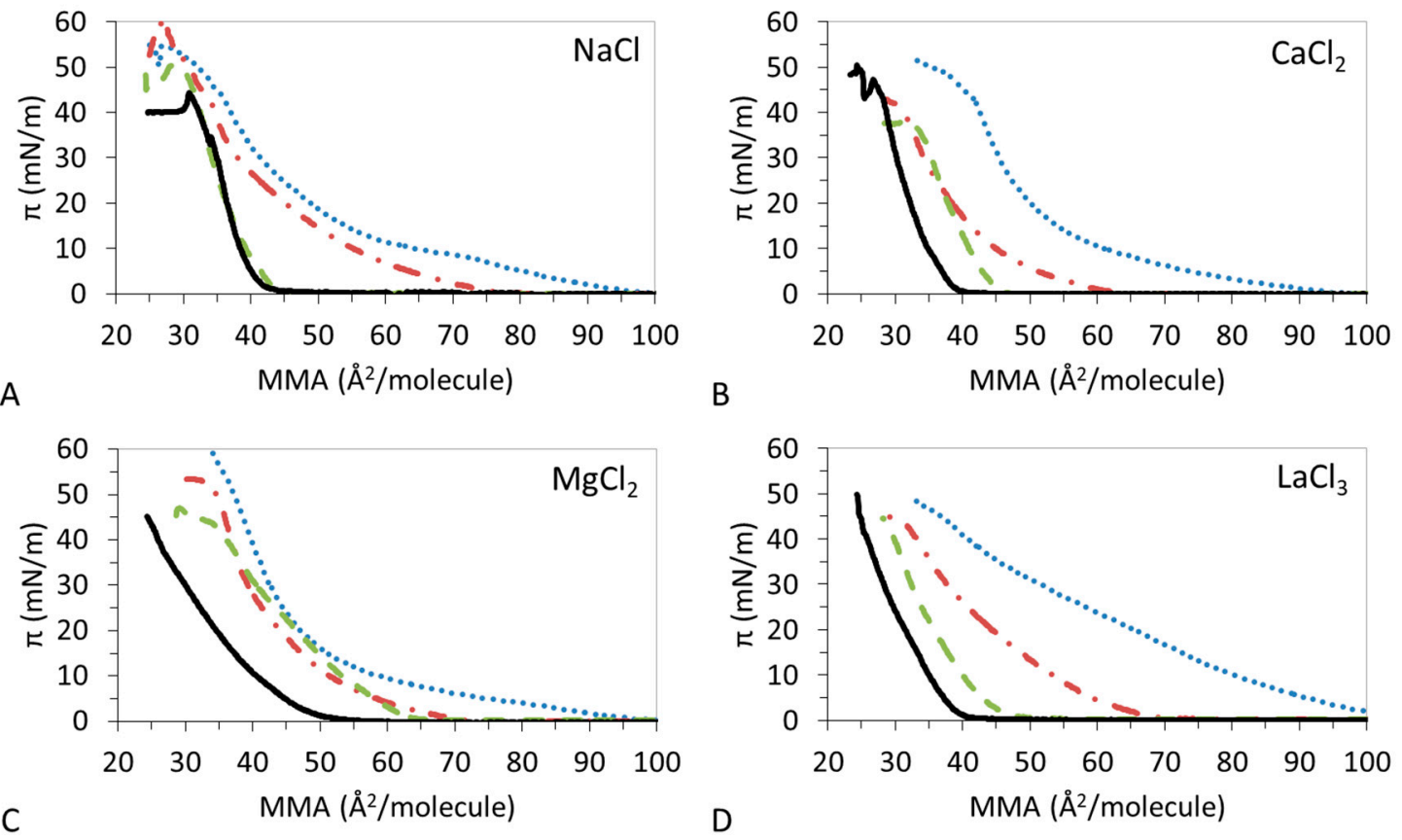

Figure 1. Surface pressure-area ( $\pi$-A) isotherms for DPPC:DPPS:CHOL spread onto solutions $I=15 \mathrm{mM}$ (A) $\mathrm{NaCl}$ (B) $\mathrm{CaCl}_{2}$ (C) $\mathrm{MgCl}_{2}$ (D) $\mathrm{LaCl}_{3}$. DPPC:DPPS (blue dotted line), DPPC:DPPS:CHOL-30 (red dash-dotted line), DPPC:DPPS:CHOL-70 (green dashed line), CHOL (black straight line). Mean values of three experiments with standard deviation $<5 \% . T=23{ }^{\circ} \mathrm{C}$, lipid composition is described in Table 1 . 
Table 2. Limiting molecular area LMA, collapse pressure $\left(\pi_{\text {coll }}\right)$, and maximum Gibbs elasticity $\left(\varepsilon_{0}\right)$ values of DPPC:DPPS:CHOL monolayers spread onto $\mathrm{NaCl} 15 \mathrm{mM}$ (Figure 1A).

\begin{tabular}{cccc}
\hline Sample & LMA & $\boldsymbol{\pi}_{\text {coll }}$ & $\varepsilon_{\mathbf{0}}(\mathbf{m N} / \mathbf{m})$ \\
\hline DPPC:DPPS 4:1 & $52 \pm 5$ & $59 \pm 5$ & $134 \pm 20$ \\
DPPC:DPPS:CHOL-30 & $48 \pm 5$ & $59 \pm 3$ & $150 \pm 10$ \\
DPPC:DPPS:CHOL-70 & $40 \pm 2$ & $53 \pm 4$ & $180 \pm 25$ \\
CHOL & $40 \pm 2$ & $44 \pm 2$ & $245 \pm 20$ \\
\hline
\end{tabular}

Table 3. Limiting molecular area LMA, collapse pressure $\left(\pi_{\text {coll }}\right)$, and maximum Gibbs elasticity $\left(\varepsilon_{0}\right)$ values of DPPC:DPPS:CHOL monolayers spread onto $\mathrm{CaCl}_{2} 5 \mathrm{mM}$ (Figure 1B).

\begin{tabular}{cccc}
\hline Sample & LMA & $\pi_{\text {coll }}$ & $\varepsilon_{\mathbf{0}}(\mathbf{m N} / \mathbf{m})$ \\
\hline DPPC:DPPS 4:1 & $55 \pm 1$ & $52 \pm 1$ & $190 \pm 10$ \\
DPPC:DPPS:CHOL-30 & $48 \pm 2$ & $42 \pm 2$ & $150 \pm 15$ \\
DPPC:DPPS:CHOL-70 & $45 \pm 2$ & $38 \pm 2$ & $210 \pm 15$ \\
CHOL & $40 \pm 2$ & $46 \pm 1$ & $230 \pm 15$ \\
\hline
\end{tabular}

Table 4. Limiting molecular area LMA, collapse pressure $\left(\pi_{\text {coll }}\right)$, and maximum Gibbs elasticity $\left(\varepsilon_{0}\right)$ values of DPPC:DPPS:CHOL monolayers spread onto $\mathrm{MgCl}_{2} 5 \mathrm{mM}$ (Figure 1C).

\begin{tabular}{cccc}
\hline Sample & LMA & $\pi_{\text {coll }}$ & $\varepsilon_{\mathbf{0}}(\mathbf{m N} / \mathbf{m})$ \\
\hline DPPC:DPPS 4:1 & $50 \pm 5$ & $64 \pm 1$ & $174 \pm 20$ \\
DPPC:DPPS:CHOL-30 & $55 \pm 5$ & $50 \pm 1$ & $180 \pm 20$ \\
DPPC:DPPS:CHOL-70 & $56 \pm 5$ & $50 \pm 2$ & $80 \pm 20$ \\
CHOL & $45 \pm 1$ & $46 \pm 1$ & $140 \pm 20$ \\
\hline
\end{tabular}

Table 5. Limiting molecular area LMA, collapse pressure $\left(\pi_{\text {coll }}\right)$, and maximum Gibbs elasticity $\left(\varepsilon_{0}\right)$ values of DPPC:DPPS:CHOL monolayers spread onto $\mathrm{LaCl}_{3} 2.5 \mathrm{mM}$ (Figure 1D).

\begin{tabular}{cccc}
\hline Sample & LMA & $\pi_{\text {coll }}$ & $\varepsilon_{\mathbf{0}}(\mathbf{m N} / \mathbf{m})$ \\
\hline DPPC:DPPS 4:1 & $85 \pm 3$ & $47 \pm 5$ & $115 \pm 20$ \\
DPPC:DPPS:CHOL-30 & $64 \pm 1$ & $50 \pm 5$ & $100 \pm 20$ \\
DPPC:DPPS:CHOL-70 & $45 \pm 2$ & $45 \pm 5$ & $170 \pm 20$ \\
CHOL & $40 \pm 1$ & $45 \pm 1$ & $150 \pm 20$ \\
\hline
\end{tabular}

Figure $1 \mathrm{~A}$ shows the impact of $\mathrm{NaCl}$ on the condensing effect of CHOL on DPPC:DPPS monolayers. Results show that the presence of CHOL in the mixture compresses the monolayer gradually, showing DPPC:DPPS:CHOL-30 close to DPPC:DPPS 4:1 and DPPS:DPPS:CHOL-70 close to CHOL. DPPC:DPPS 4:1 shows a LE-LC coexistence region which is reduced by the presence of CHOL in DPPC:DPPS:CHOL-30, however the LMAs are similar in both cases. Then, DPPC:DPPS:CHOL-70 and CHOL display a similar LC film with equally similar LMAs values (Table 2). Hence, the LMA of the film decreases with the amount of CHOL to practically match that pure CHOL and the $\pi_{\text {coll }}$ follows a very similar trend (Table 2). The condensing effect of CHOL on DPPC:DPPS films in the presence of $\mathrm{Na}^{+}$improves gradually the elasticity of the films.

Figure 1B shows that the condensation of DPPC:DPPS by CHOL proceeds differently in the presence of $\mathrm{Ca}^{2+}$ compared to $\mathrm{Na}^{+}$. DPPC:DPPS:CHOL-30 and DPPC:DPPS:CHOL-70 display a reduced LE regime and attain similar LMAs (Table 3) which remain above the LMA of CHOL. The ternary system also shows lower $\pi_{\text {coll }}$ as compared to both pure systems (Table 3 ). The $\varepsilon_{0}$ of the film shows a complex behavior decreasing slightly for DPPC:DPPS:CHOL-30 and then increasing for DPPC:DPPS:70 to practically match that of CHOL (Table 3).

Despite having a similar valence, the effect of $\mathrm{Mg}^{2+}$ is different to that of $\mathrm{Ca}^{2+}$ (Figure 1C). DPPC:DPPS:CHOL-30 and DPPC:DPPS:CHOL-70 appear very similar to DPPC:DPPS 4:1 and the main 
effect of CHOL seems to be a slight reduction of LE regime. The LMAs of the ternary system remain close to that of lipids or even slightly higher (Table 4 ). $\pi_{\text {coll }}$ displays an intermediate value between that of lipids and CHOL (Table 3). Finally, the $\varepsilon_{0}$ of the film now decreases with the amount of CHOL (Table 3), indicative of a less cohesive state of the film attained in the presence of CHOL. However, the presence of $\mathrm{Mg}^{2+}$ also reduces the $\varepsilon_{0}$ of pure CHOL monolayer as will be analyzed in detail later.

Similar to $\mathrm{Mg}^{2+}$, the presence of $\mathrm{La}^{3+}$ already affects the shape of the pure components (Figure 1D) and this affects the condensation which appears now very gradual as the amount of CHOL increases in the system (Figure 1D), reducing the LMAs progressively (Table 5). The shapes of the monolayers appear very smooth in all cases and $\pi_{\text {coll }}$ displays similar values. The presence of $\mathrm{La}^{3+}$ also reduces the $\varepsilon_{0}$ of pure CHOL monolayer as does $\mathrm{Mg}^{2+}$, indicative of the formation of LE films (Table 5). However, in contrast to the effect of $\mathrm{Mg}^{2+}$, the condensing effect of CHOL on DPPC:DPPS films, in the presence of $\mathrm{La}^{3+}$, improves again the elasticity of the films. This is similar to $\mathrm{Na}^{+}$and opposite to $\mathrm{Mg}^{2+}$ while $\mathrm{Ca}^{2+}$ showed a complex trend.

\section{2. $\Delta V-A$ Isotherms}

Figure 2 shows the measured $\Delta V-A$ isotherms of the monolayers reported in Figure 1 . The shape of these curves accounts for the orientation of the lipid molecules within the monolayer. In LE films $\Delta V$ presents a monotonous increase with small slope as the film is compressed. LC states of the monolayer present a steep rise of the $\Delta V$ while a non-monotonous increase is indicative of the presence of $L E$ and LC states in the monolayer.
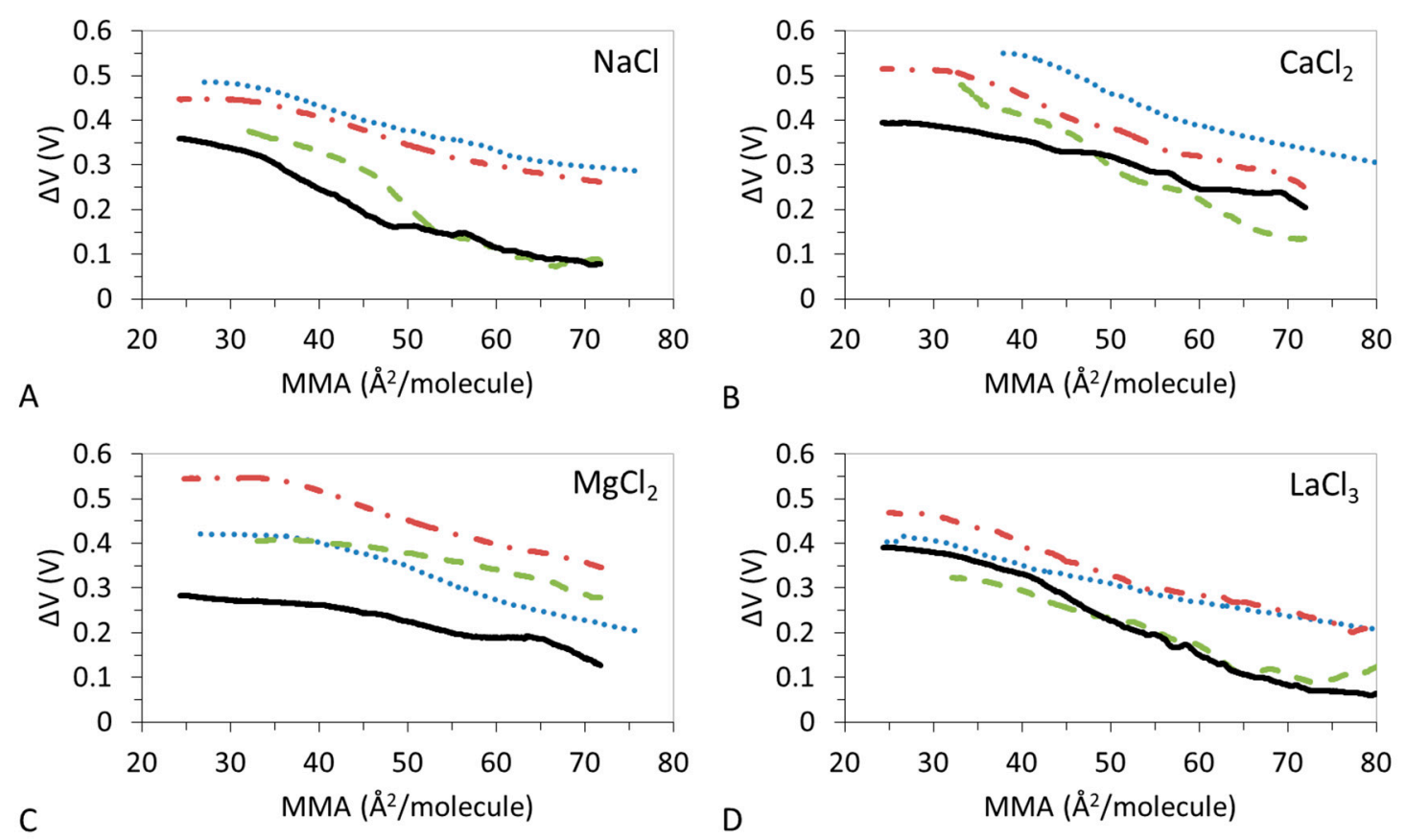

Figure 2. Surface potential-area $(\triangle V-\mathrm{A})$ isotherms for DPPC:DPPS:CHOL spread onto solutions $I=15 \mathrm{mM}$ (A) $\mathrm{NaCl}$ (B) $\mathrm{CaCl}_{2}$ (C) $\mathrm{MgCl}_{2}$ (D) $\mathrm{LaCl}_{3}$. DPPC:DPPS (blue dotted line), DPPC:DPPS:CHOL-30 (red dash-dotted line), DPPC:DPPS:CHOL-70 (green dashed line), CHOL (black line). Mean values of three experiments with standard deviation $<10 \% . \quad T=23{ }^{\circ} \mathrm{C}$, lipid composition is described in Table 1.

Figure 2A shows the $\Delta V$-isotherms of DPPC:DPPS:CHOL in the presence of $\mathrm{Na}^{+} . \Delta V$ confirms that the presence of $\mathrm{CHOL}$ in the mixture compresses the monolayer to reach a typical curve of $\mathrm{LC}$ monolayer exhibiting a steep increase of the $\Delta V$. Similar to the findings in Figure 1A, DPPC:DPPS 4:1, and DPPC:DPPS-30 display similar shapes while DPPC:DPPS-70 and CHOL display similar shapes, indicative a of similar conformations states changing from LE to LC state. 
The $\triangle V-A$ isotherms of DPPC:DPPS:CHOL in the presence of $\mathrm{Ca}^{2+}$ show a complex trend (Figure 2B) in agreement also with findings from Table 3. The $\Delta V-A$ isotherms recorded for DPPC:DPPS 4:1 and DPPC:DPPS:CHOL-30 display similar monotonous increases consistent with LE films, while DPPC:DPPS:CHOL-70 and CHOL display slightly higher slopes indicative of a more condensed state. In the presence of $\mathrm{Mg}^{2+}$ (Figure 2C), the $\Delta V-A$ isotherms of $\mathrm{CHOL}$ shows a monotonous smooth increase indicative of a LE film in the presence of $\mathrm{Mg}^{2+}$ in agreement with results in Figure $1 \mathrm{C}$ and Table 4. Then, $\Delta V-A$ isotherms of ternary systems, DPPC:DPPS:CHOL-30 and DPPC:DPPS:CHOL-70, lie parallel to DPPC:DPPS 4:1 but above both pure systems (Figure 2C). This type of behavior is only seen for $\mathrm{Mg}^{2+}$. The reduction of $\varepsilon_{0}$ with the amount of CHOL reported in Table 4 suggests reduced lateral molecular interactions in the presence of $\mathrm{Mg}^{2+}$.

In the presence of $\mathrm{La}^{3+}$, all the $\Delta V-A$ isotherms show a monotonous smooth increase (Figure 2D) indicative of LE films in agreement with Figure 1D and Table 5. Similar to the effect of $\mathrm{Na}^{+}$, the $\Delta V-A$ isotherms of the ternary system appear in between that of pure components, with DPPC:DPPS 4:1 similar to DPPC:DPPS:CHOL-30 and DPPC:DPPS:CHOL-70 similar to CHOL, but these do not seem to reach values corresponding to the LC state (Tables 2 and 5). Thus, the condensing effect of CHOL on DPPC:DPPS films in the presence of $\mathrm{La}^{3+}$ implies a gradual change of the orientation of the lipid molecules in the monolayer, which results in an increase of the $\varepsilon_{0}$ (Table 2) owing to condensation by CHOL but in a way that the systems retain a LE state.

\subsection{Micro-BAM Images}

Figures 3 and 4 display a set of images taken by Micro-BAM of the monolayers reported in Figure 1 under the same experimental conditions.

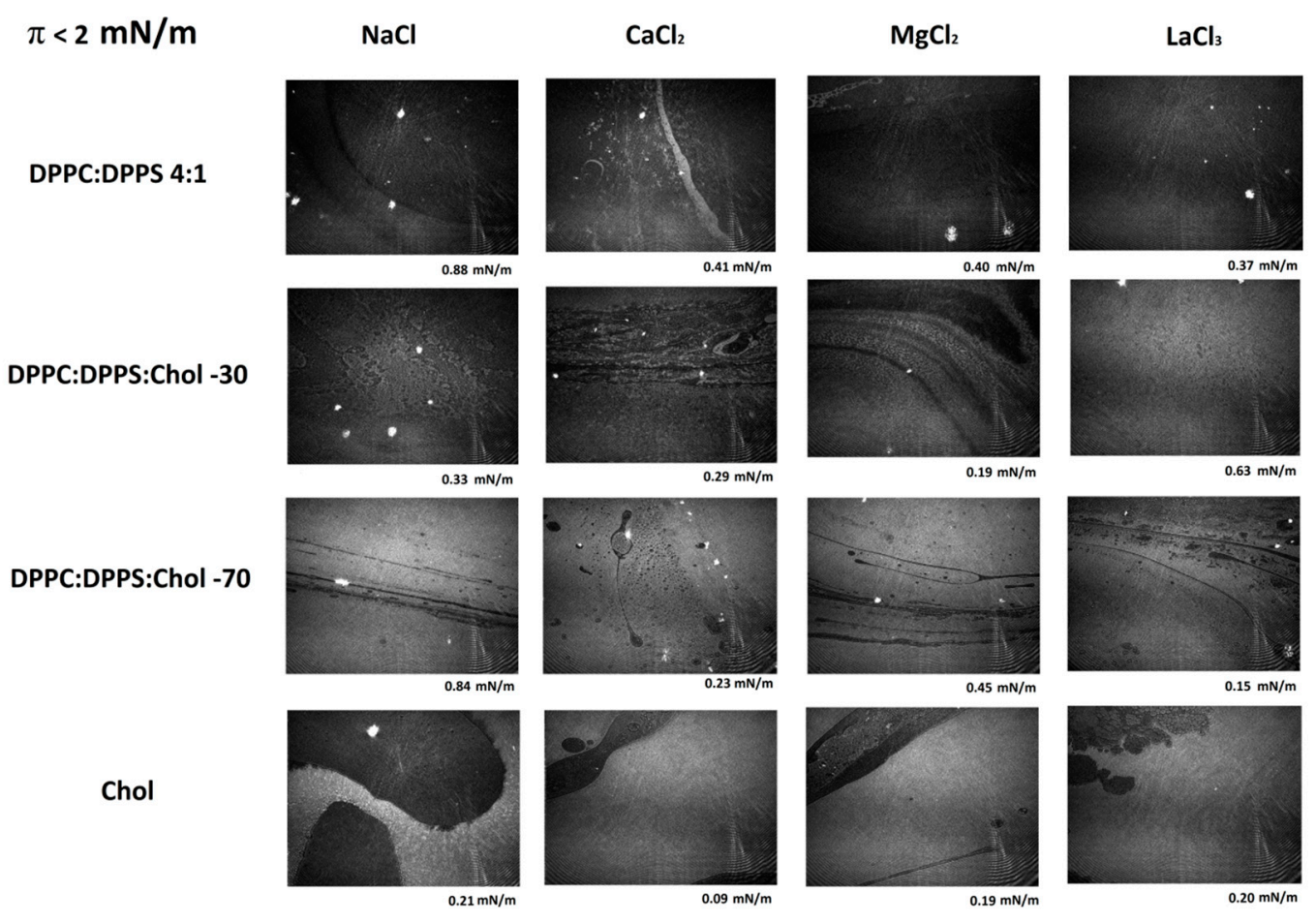

Figure 3. Micro-Brewster Angle Microscopy (Micro-BAM) images of the effect of electrolyte on DPPC:DPPS:CHOL monolayers at low compression states $(\pi<2 \mathrm{mN} / \mathrm{m})$. The images correspond to the $\pi-A$ isotherms plotted in Figure 1. 


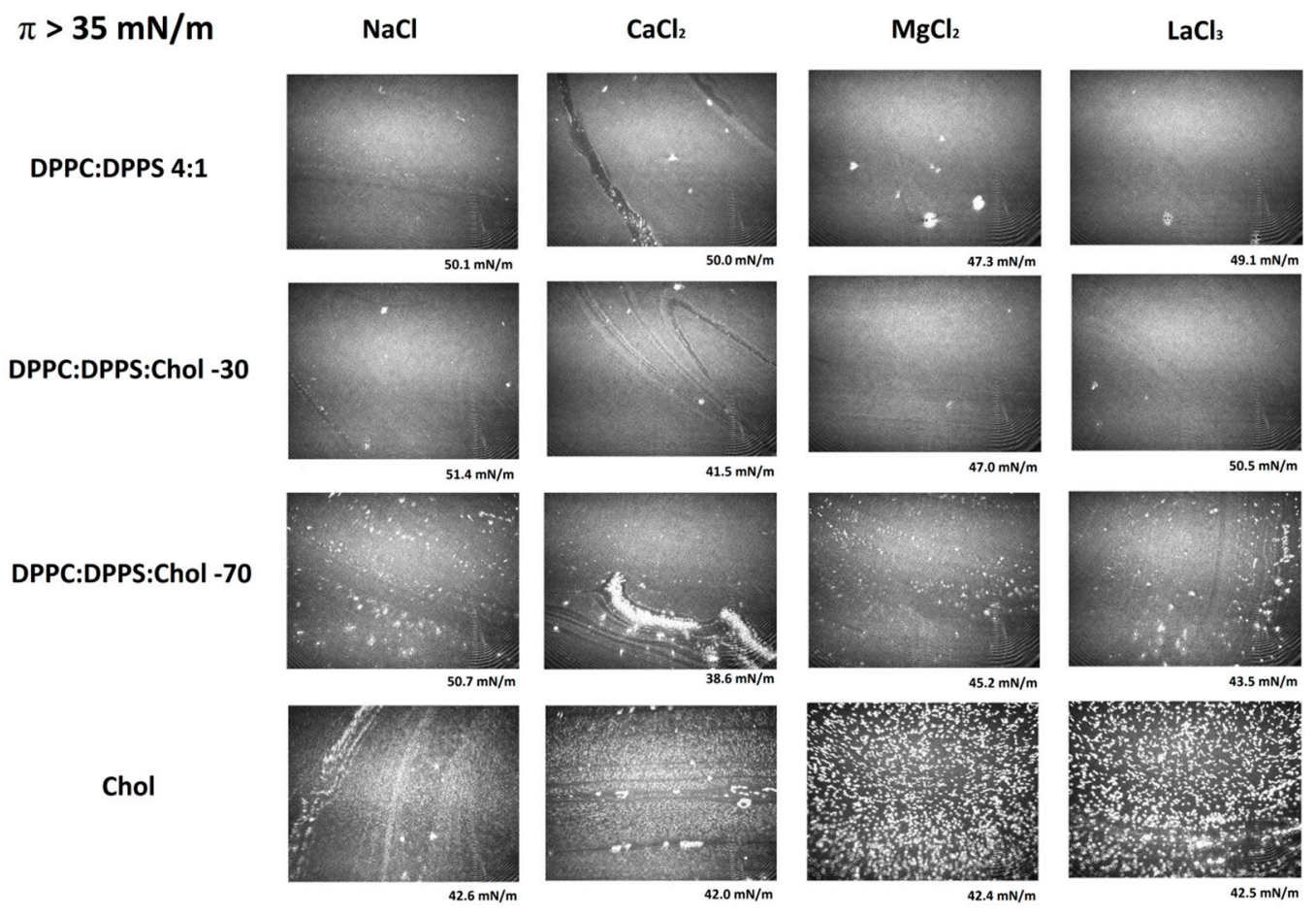

Figure 4. Micro-BAM images of the effect of electrolyte on DPPC:DPPS:CHOL monolayers at high compression states $(\pi>35 \mathrm{mN} / \mathrm{m})$. The images correspond to the $\pi$-A isotherms plotted in Figure 1 .

Figure 3 shows a series of representative Micro-BAM images taken at the lowest compression states of the monolayer, with $\pi<2 \mathrm{mN} / \mathrm{m}$; namely at large MMAs. In this range, the lipid mixture undergoes a first-order phase transition as the surface density increases for lower MMAs. Different phases are distinguishable in the Micro-BAM image by a difference in reflectivity. Gas, LE, and LC films differ in the orientation of molecules and, hence, in the monolayer thickness. The thicker LC phase appears brighter (more reflective) than the thinner LE or gas phase which appear darker (less reflective). During a phase transition, domains of different brightness are observed simultaneously in the image. In Figure 3, the brightness of the images increases as the amount of CHOL increases in the mixture. In the case of CHOL, large fluid domains of coexisting gas/LE (dark) and LC phases (bright) can be seen. These domains also appear in the systems composed of DPPC:DPPS:CHOL as the amount of CHOL increases in the system whereas they are hardly visible in the pure DPPC:DPPS 4:1 system.

Figure 4 shows a series of representative Micro-BAM images taken at the final stages of compression of DPPC:DPPS:CHOL films, close to collapse (Figure 1). The MMA is now very small and the lipids in the monolayer are highly packed. Micro-BAM images revealed the presence of bright spots as the amount of $\mathrm{CHOL}$ increases in the mixture. Monolayers of insoluble compounds can be compressed to very close-packed structures at low MMAs. Beyond the maximum surface density, the monolayer starts to buckle and undergoes a collapse where a variety of collapse structures appear. The images of the collapse of a CHOL monolayer agree with research literatures, showing collapse structures as bright, rod-like domains and crystals $[17,34]$. The appearance of these spots in the DPPC:DPPS:CHOL could be indicative of the orientation change of the molecules owing to condensation by CHOL. These spots only appear in the presence of $\mathrm{CHOL}$ as the condensation proceeds and they are more visible in the case of $\mathrm{Ca}^{2+}$ owing to the high condensation reached.

\subsection{Effect of Ions}

In order to unravel the complex mechanism and shed light on the impact of specific ion effects on the condensation of DPPC:DPPS 4:1 by CHOL, we replotted the experimental results shown in Figures 1 and 2. In particular, Figures 5-8 show the $\pi-A$ and $\Delta V-A$ isotherms obtained for each lipidic 
system in the presence of the different ions, hence, allowing a direct comparison of the specific ion effect on the surface conformation and lateral packing of lipids.
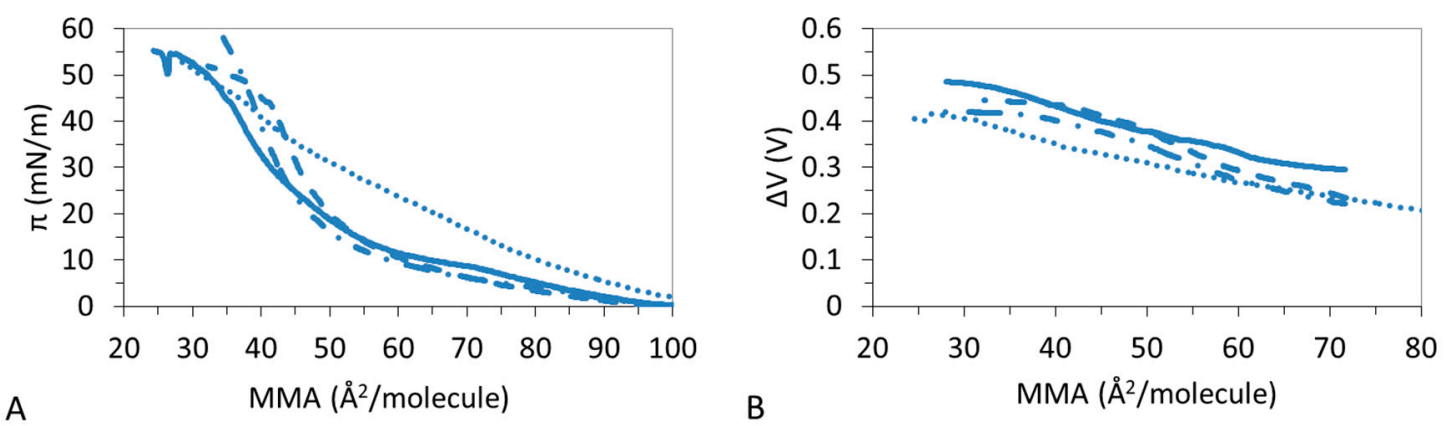

Figure 5. Effect of electrolyte on DPPC:DPPS 4:1 monolayers (A) $\pi-A$ and (B) $\Delta V-A$ isotherms. $15 \mathrm{mM}$ $\mathrm{NaCl}$ (straight line), $5 \mathrm{mM} \mathrm{CaCl}_{2}$ (dashed line), $5 \mathrm{mM} \mathrm{MgCl}_{2}$ (dash-dotted line), $2.5 \mathrm{mM} \mathrm{LaCl}_{3}$ (dotted line). Curves replotted from Figure 1.
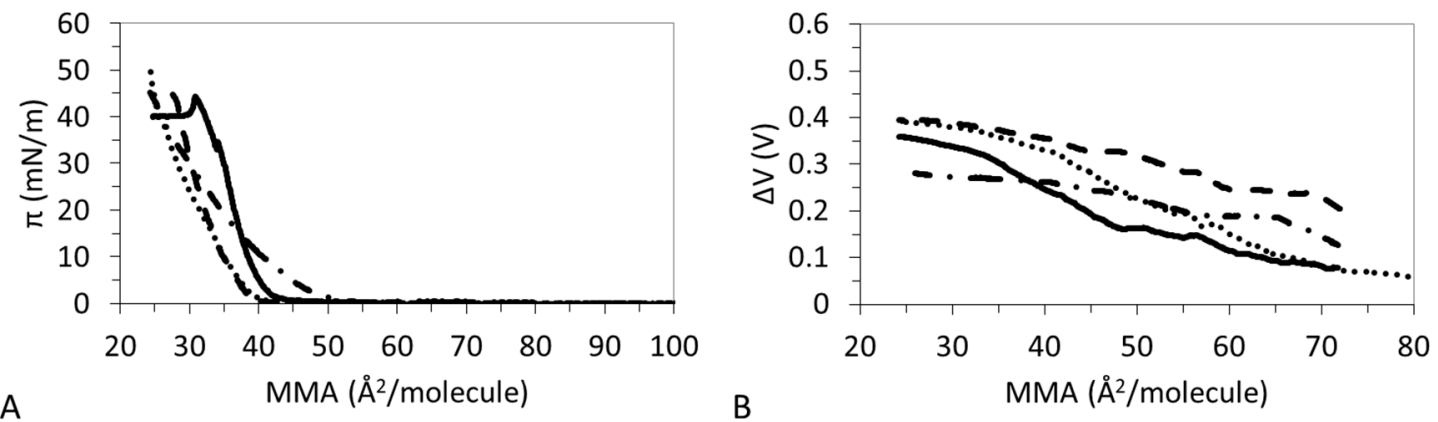

Figure 6. Effect of electrolyte on CHOL monolayers (A) $\pi$ - $A$ and (B) $\Delta V-A$ isotherms. $15 \mathrm{mM} \mathrm{NaCl}$ (straight line), $5 \mathrm{mM} \mathrm{CaCl}_{2}$ (dashed line), $5 \mathrm{mM} \mathrm{MgCl}_{2}$ (dash-dotted line), $2.5 \mathrm{mM} \mathrm{LaCl}_{3}$ (dotted line), respectively. Curves replotted from Figures 1 and 2.
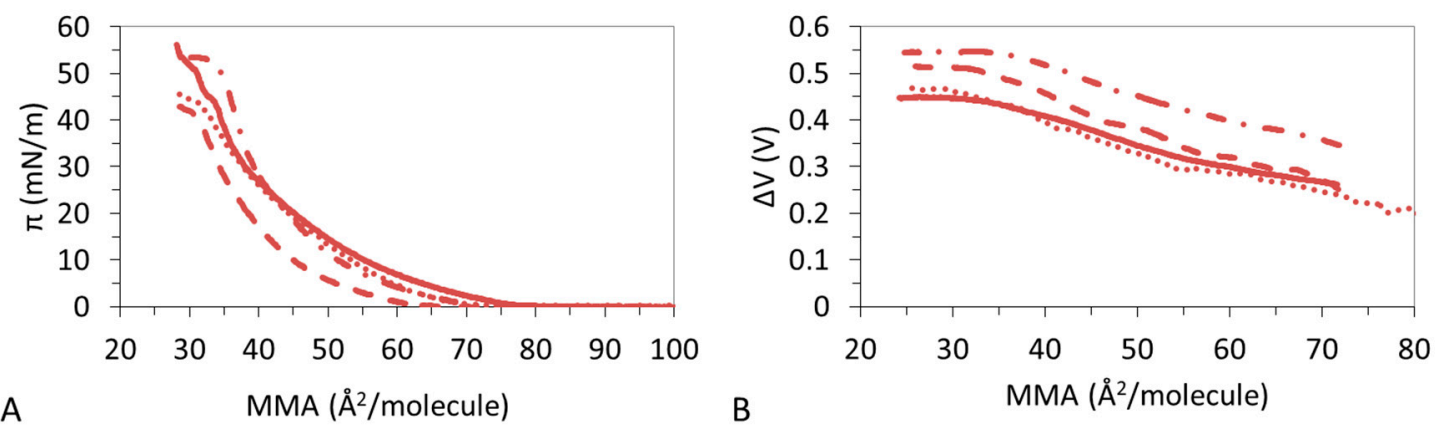

Figure 7. Effect of electrolyte on DPPC:DPPS:CHOL-30 monolayers. (A) $\pi-A$ and (B) $\Delta V-A$ isotherms. $15 \mathrm{mM} \mathrm{NaCl}$ (straight line), $5 \mathrm{mM} \mathrm{CaCl}_{2}$ (dashed line), $5 \mathrm{mM} \mathrm{MgCl}_{2}$ (dash-dotted line), $2.5 \mathrm{mM} \mathrm{LaCl}_{3}$ (dotted line). Curves replotted from Figures 1 and 2.

Figure 5A shows that DPPC:DPPS 4:1 presents a LE-LC transition which is more pronounced in the presence of $\mathrm{Mg}^{2+}$ and $\mathrm{Ca}^{2+}$ but vanishes in the presence of $\mathrm{La}^{3+}$. This is corroborated by the trend of the $\varepsilon_{0}$ (Tables 2-5) which increases in the presence of divalent ions and decreases for $\mathrm{La}^{3+}$ and by the $\Delta V$-A isotherms which shows non-monotonous increases only for the ternary system.

Figure 6A,B evidences that CHOL molecules remain in a 2D gaseous state upon compression of the monolayer to sharply enter into a condensed/solid phase as the compression proceeds. Namely, CHOL forms a LC film, characterized by a high $\varepsilon_{0}$ in the presence of $\mathrm{Na}^{+}$(Table 2) and a LE film with lower $\varepsilon_{0}$ in the presence of $\mathrm{La}^{3+}$ (Table 5). The effect of divalent ions is complex; $\mathrm{Ca}^{2+}$ seems to retain 
the LC state of CHOL with a high $\varepsilon_{0}$ (Table 4) and significant slope in $\Delta V$ (Figure 6B), while $\mathrm{Mg}^{2+}$ lowers the $\varepsilon_{0}$ to a LE film (Table 4 ) and so does the slope in $\Delta V$ (Figure 6B).
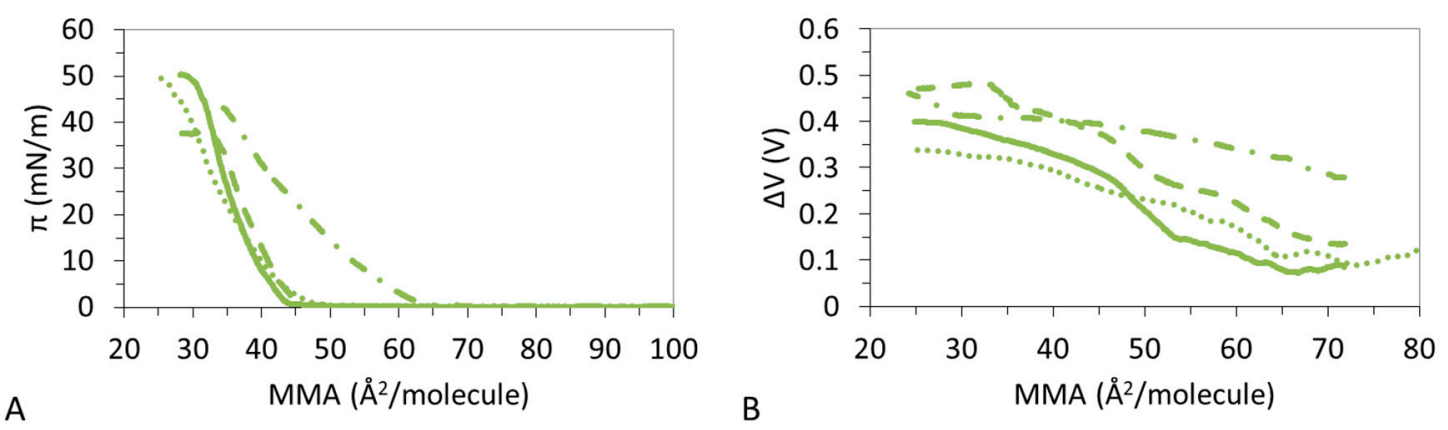

Figure 8. Effect of electrolyte on DPPC:DPPS:CHOL-70 monolayers. (A) $\pi-A$ and (B) $\Delta V-A$ isotherms. $15 \mathrm{mM} \mathrm{NaCl}$ (straight line), $5 \mathrm{mM} \mathrm{CaCl}_{2}$ (dashed line), $5 \mathrm{mM} \mathrm{MgCl}_{2}$ (dash-dotted line), $2.5 \mathrm{mM} \mathrm{LaCl}_{3}$ (dotted line). Curves replotted from Figures 1 and 2.

Figure 7A,B shows that DPPC:DPPS:CHOL-30 molecules remain in a LE state during all the compression and values obtained for $\varepsilon_{0}$ in the presence of different ions remain within the limits of LE films (Tables 2-5) highlighting different lateral interactions for different ions. In particular, $\varepsilon_{0}$ is higher in the presence of divalent ions (Tables 3 and 4) compared to $\mathrm{Na}^{+}$and $\mathrm{La}^{3+}$ (Tables 2 and 5). This increased interaction is also reflected in the higher value of $\Delta V$ obtained in the presence of divalent cations (Figure 7B).

Figure 8A shows that the ternary system DPPC:DPPS:CHOL-70 has a clear specific interaction with $\mathrm{Mg}^{2+}$, possibly due to the high amount of $\mathrm{CHOL}$ in the mixture which also interacted specifically with $\mathrm{Mg}^{2+}$ (Figure 5). In the presence of $\mathrm{Mg}^{2+}$, DPPC:DPPS:CHOL-70 remains in a LE state, as given by a monotonous increase of $\Delta V$ (Figure $8 \mathrm{~B}$ ) and low $\varepsilon_{0}$ (Table 4). Conversely, $\mathrm{Na}^{+}, \mathrm{Ca}^{2+}$, and $\mathrm{La}^{3+}$ provide non-monotonous increases of $\Delta V$ (Figure $8 \mathrm{~B}$ ) and higher values of $\varepsilon_{0}$ (Table 2, Table 3, and Table 5) indicative of a LC state. Again, the higher value of $\Delta V$ obtained, only in the presence of $\mathrm{Mg}^{2+}$ (Figure 4B), might corroborate the existence of a specific interaction.

\section{Discussion}

The presence of ions adsorbed at the lipid interface can modify the conformation and orientation of lipids as well as the organization of water molecules and, in turn, their interaction with CHOL and the overall condensation phenomenon. Results presented here show a complex scenario in which different variables act together. In the absence of salt, it was demonstrated that the presence of CHOL increases the ordering of neighboring lipids and contributes to increase the elasticity/compressibility of the films at once $[2,35]$. Moreover, the condensing effect induced by CHOL molecules, when they interact with other lipids, is directly linked to the orientation CHOL molecular [2,9,16,47]. Although this condensing effect generally persists in the presence of salt, ions have a strong influence on how this condensation takes place, as it can be seen in our experiments (Figure 6). However, the effect of the electrolyte on ternary monolayers, made of mixtures of $\mathrm{CHOL}$ with zwitterionic and anionic phospholipids is twofold. On one hand, ions may modify the structure of lipid films (in the absence of CHOL) as demonstrated in Figure 5. On the other hand, when CHOL is included in the monolayer, ions must compete with $\mathrm{CHOL}$ in their interactions with lipids. In the case of ternary monolayers of DPPC:DPPS:CHOL analyzed in this study, their surface properties clearly depend on the type of ions and on the lipids ratio (Figures 7 and 8). There are some available data of some of the mixtures in different researches, which can shed light on the different types of interactions concurring. Accordingly, in order to understand the molecular mechanism behind the CHOL-lipid interactions mediated by cations, we will compare our results with previously obtained in the literature. For instance, the effect of $\mathrm{Ca}^{2+}$ on $\pi-A$ isotherms of DPPC/DPPS 4:1 monolayers was studied at the air-water interface [48-50]. 
In particular, Ross et al. employed fluorescence microscopy in conjunction with $\pi-A$ isotherms, time-of-flight secondary ion mass spectrometry (TOF-SIMS) imaging, scanning electron microscopy (SEM), and lateral force microscopy to prove that $\mathrm{Ca}^{2+}$ preferentially binds to negatively charged DPPS molecules [48]. This result was also confirmed by magic angle spinning (MAS) and nuclear magnetic resonance (NMR) measurements in combination with MD simulations [51]. However, these conformation changes are not reflected in significant changes of $\pi-A$ isotherms of DPPC/DPPS 4:1 in the presence of $\mathrm{Ca}^{2+}[48,49]$ and the shape of the isotherm was unaffected, in agreement with our results. In contrast to the case of $\mathrm{Na}^{+}, \mathrm{Ca}^{2+}$, and $\mathrm{Mg}^{2+}$, the presence of $\mathrm{La}^{3+}$ importantly affects the shape of the DPPC/DPPS 4:1 isotherm (Figure 5). This can be attributed to a different binding mode of trivalent cation to PC and PS lipids as compared to monovalent and divalent cations [39,41]. Different binding constants are related to the different dehydration ability of each ion on different lipids. In the case of $\mathrm{La}^{3+}$, calorimetric measurements show that the binding of this cation to PS lipids is endothermic and entropy driven [52]. The dominant entropic contribution is due mainly to the liberation of solvating water molecules from lipid headgroups. For the case of PC lipids, calorimetric measurements give values of free energy larger than in the case of PS.

However, the above mentioned specific ion-lipid interaction importantly change when CHOL is added into the lipid film. Generally, the miscibility and stability of bilayers and monolayers made of binary mixtures of zwitterionic lipids and CHOL is related to the orientation of lipid molecules. Concretely, the presence of CHOL in the monolayer limits the mobility of zwitterionic lipids inducing an upright orientation of their hydrocarbon chains, thus enhancing van der Waals interactions and the formation of hydrogen bonds. In fact, the differences in the condensation induced by CHOL on phospholipid films may be the result of differences in molecular organization of pure lipids films rather than specific CHOL-lipid interactions [34,47,53-55]. In fact, therein the ability of CHOL to build clusters and the most common locations of $\mathrm{CHOL}$ in zwitterionic films has been investigated by fluorescence spectroscopy, X-ray diffraction, neutron scattering, and NMR. However, if charged lipids are also included in the lipid mixture, the situation drastically changes. The localization of CHOL in lipid monolayers depends strongly on the electric charge on the hydrophilic headgroup of the lipid rather than on the ordering of the hydrocarbon tails [56]. Electrostatic interaction tends to enhance the stability of the lipid films, being this electric interaction modulated by the presence of cations. Under this scenario, the presence of salt in the subphase plays an important role increasing the monolayer condensation, elasticity, stability, and packing density, especially for the case of divalent cations [17]. This feature can be inferred from $\Delta V-A$ isotherms (Figure 3). Normally $\Delta V$ of lipid monolayers is proportional to the normal dipole moment per molecule, which in turn provides further evidence of distribution of the cations in the lipid monolayers [46]. In this sense, our results show how divalent cations have a stronger effect on the structure of the monolayers than monovalent or trivalent cations (Figures 5-8). For instance, Casper and co-workers reported a higher impact of divalent cations on $\Delta V$ for DPPC monolayers with respect to monovalent ions [57]. These authors related the increase of $\Delta V$ to cation binding modes and affinities for the zwitterionic group. Wydro and co-workers found that for DPPE:DPPS:CHOL films compressed on water and on a subphase containing $\mathrm{Ca}^{2+}$, the interactions between films components are less attractive (or more repulsive) than those obtained for the pure components (DPPE:DPPS and CHOL:CHOL) [36]. On the other hand, these authors observed that DPPE:DPPS:CHOL monolayers spread on $\mathrm{Na}^{+}$were similar to those for DPPS:CHOL films. As a consequence, they concluded that phosphatidylserines, despite their lower concentration in membranes, strongly influence the properties of complex lipid systems.

In order to deepen into the ability of $\mathrm{Mg}^{2+}$ to reorganize DPPS-DPPC films, Schultz and co-workers applied infrared spectroscopic techniques to examine this system both for assessing bilayer microdomain formation and for determining lipid acyl chain reorganizations within the hydrophobic core of the membranes in the presence of $\mathrm{Mg}^{2+}$ [58]. Therein, the authors demonstrate that $\mathrm{Mg}^{2+}$ induces both the aggregation and the fusion of the lipid assemblies as a function of the ratio of DPPS to DPPC. Accordingly, if a high proportion of $\mathrm{CHOL}$ is included in the lipid film it is reasonable to believe 
that the role played by CHOL in the lipid film will be influenced by the presence of this divalent cation. In particular, our results seem to indicate that $\mathrm{Mg}^{2+}$ breaks the process of condensation induced by CHOL. Moreover, the irregular behavior in the $\varepsilon_{0}$ of the film shown in Table 4 is a consequence of the opposite effects induced by $\mathrm{CHOL}$ and $\mathrm{Mg}^{2+}$ which compete at the interface. The lift of the isotherms corresponds to the transition from gaseous to condensed state, with the CHOL molecules oriented with the hydroxyl group pointing towards the water phase and a condensed packing of the hydrophobic body of the CHOL molecule [23]. The specific interaction of $\mathrm{Mg}^{2+}$ with CHOL results in this condensation occurring at higher MMAs owing to a less condensed packing state and orientation (Figure 6). This dissimilar behavior induced by divalent cations agrees with the fact that CHOL promotes divalent cation-dependent formation of hexagonal phases in mixtures of PC with PS. In the absence of CHOL, different aggregation kinetic and morphologies for aggregates of PS vesicles induced by $\mathrm{Ca}^{2+}$ and $\mathrm{Mg}^{2+}$ are experimentally reported [37,38]. However, CHOL strongly influences the kinetics of contents leakage following divalent cation-induced aggregation of lipid vesicles [59]. In general, $\mathrm{CHOL}$ increases the rate of magnesium-induced contents leakage from mixed zwitterionic/anionic lipid vesicles. This feature becomes more important as the ratio of PC increases in the bilayer.

\section{Conclusions}

In the presence of $\mathrm{Na}^{+}$, DPPC:DPPS 4:1 undergoes a gradual condensation by CHOL in which the lipids form LC condensed films as the molecules reorient and the $\varepsilon_{0}$ increases. In the presence of $\mathrm{La}^{3+}$, DPPC:DPPS 4:1 undergoes a gradual condensation by CHOL in which the lipids seem to remain in a LE state with increased cohesivity $\left(\varepsilon_{0}\right)$ as the amount of $\mathrm{CHOL}$ increases in the mixture. In the presence of divalent cations, $\mathrm{Ca}^{2+}$ and $\mathrm{Mg}^{2+}$, the condensation shows important differences possibly owing to specific ion correlations. The $\varepsilon_{0}$ of the film shows a complex behavior dependent on the ion and on the amount of CHOL. $\mathrm{Mg}^{2+}$ reduces importantly the cohesivity of the CHOL film as the condensation by $\mathrm{CHOL}$ reduces the lateral molecular interactions. Conversely, in the presence of $\mathrm{Ca}^{2+} \mathrm{CHOL}$ induced condensation occurs in a LC state with similar lateral molecular interaction and possibly molecular orientation to that of CHOL. In summary, our results show that the condensation of model lipid films in the presence of CHOL depends on the combined action of ions and CHOL. Ion-lipid binding is ion specific and affects the dehydration ability of the film and the capacity to prevent the formation of hydrogen bonds. These factors are determinant in the condensation of lipids by $\mathrm{CHOL}$ at the air-water interface.

Author Contributions: Conceptualization and Methodology, A.M.M., J.M.V.; Data Acquisition, T.D.C.S., Y.Y.; Formal Analysis, A.M.M., J.M.V., and T.D.C.S.; Writing-Original Draft Preparation, A.M.M., J.M.V.; Writing - Review and Editing, A.M.M. and J.M.V.; Supervision, A.M.M.; Project Administration, T.D.C.S.; Funding Acquisition, J.M.V., A.M.M., and T.D.C.S.

Funding: This research was funded by "Ministerio de Economía y Competitividad (MINECO), Plan Nacional de Investigación, Desarrollo e Innovación Tecnológica (I + D + i)": Grant RYC-2012-10556, Projects MAT2015-63644-C2-1-R, RTI2018-101309-B-C21 and FIS2016-80087-C2-1-P, and European Regional Development Fund (ERDF). “Universidad de Granada” CEI-BIOTIC-BS14.2015. This study was also partially supported by "Consejería de Conocimiento, Investigación y Universidad, Junta de Andalucía", ref. SOMM17/6105/UGR and SOMM17/6109/UGR.

Conflicts of Interest: The authors declare no conflict of interest.

\section{References}

1. Alberts, B. Molecular Biology of the Cell; Garland Science: New York, NY, USA, 2015.

2. Ikonen, E. Cellular cholesterol trafficking and compartmentalization. Nat. Rev. Mol. Cell Biol. 2008, 9, 125-138. [CrossRef] [PubMed]

3. Levitan, I.; Barrantes, F.J. Cholesterol Regulation of Ion Channels and Receptors; John Wiley \& Sons: Hoboken, NJ, USA, 2012. 
4. Zhang, J.; Xue, R.; Ong, W.-Y.; Chen, P. Roles of cholesterol in vesicle fusion and motion. Biophys. J. 2009, 97, 1371-1380. [CrossRef] [PubMed]

5. Coderch, L.; Fonollosa, J.; De Pera, M.; Estelrich, J.; De La Maza, A.; Parra, J.L. Influence of cholesterol on liposome fluidity by EPR: Relationship with percutaneous absorption. J. Control. Release 2000, 68, 85-95. [CrossRef]

6. Cabrera, I.; Abasolo, I.; Corchero, J.L.; Elizondo, E.; Gil, P.R.; Moreno, E.; Faraudo, J.; Sala, S.; Bueno, D.; González-Mira, E.; et al. $\alpha$-galactosidase a loaded nanoliposomes with enhanced enzymatic activity and intracellular penetration. Adv. Healthc. Mater. 2016, 5, 829-840. [CrossRef] [PubMed]

7. Muñoz-Úbeda, M.; Rodríguez-Pulido, A.; Nogales, A.; Martín-Molina, A.; Aicart, E.; Junquera, E. Effect of lipid composition on the structure and theoretical phase diagrams of DC-Chol/DOPE-DNA lipoplexes. Biomacromolecules 2010, 11, 3332-3340. [CrossRef] [PubMed]

8. Paiva, D.; Martín-Molina, A.; Cardoso, I.; Quesada-Pérez, M.; do Carmo Pereira, M.; Rocha, S. The effect of a fluorinated cholesterol derivative on the stability and physical properties of cationic DNA vectors. Soft Matter 2013, 9, 401-409. [CrossRef]

9. de Meyer, F.; Smit, B. Effect of cholesterol on the structure of a phospholipid bilayer. Proc. Natl. Acad. Sci. USA 2009, 106, 3654-3658. [CrossRef]

10. Finegold, L. Cholesterol in Membrane Models; CRC Press: Boca Raton, FL, USA, 1993.

11. Ege, C.; Ratajczak, M.K.; Majewski, J.; Kjaer, K.; Lee, K.Y.C. Evidence for lipid/cholesterol ordering in model lipid membranes. Biophys. J. 2006, 91, L01-L03. [CrossRef]

12. van Meer, G.; Voelker, D.R.; Feigenson, G.W. Membrane lipids: Where they are and how they behave. Nat. Rev. Mol. Cell Biol. 2008, 9, 112-124. [CrossRef]

13. Adhyapak, P.R.; Panchal, S.V.; Murthy, A.V.R. Cholesterol induced asymmetry in DOPC bilayers probed by AFM force spectroscopy. Biochim. Biophys. Acta Biomembr. 2018, 1860, 953-959. [CrossRef]

14. Leathes, J.B. Croonian lectures on the rôle of fats in vital phenomena. Lancet 1925, 205, 853-856. [CrossRef]

15. Dynarowicz-Łatka, P.; Haç-Wydro, K. Interactions between phosphatidylcholines and cholesterol in monolayers at the air/water interface. Colloids Surf. B Biointerfaces 2004, 37, 21-25. [CrossRef] [PubMed]

16. Jurak, M. Thermodynamic aspects of cholesterol effect on properties of phospholipid monolayers: Langmuir and Langmuir-blodgett monolayer study. J. Phys. Chem. B 2013, 117, 3496-3502. [CrossRef] [PubMed]

17. Korchowiec, B.; Paluch, M.; Corvis, Y.; Rogalska, E. A Langmuir film approach to elucidating interactions in lipid membranes: 1,2-dipalmitoyl-sn-glycero-3-phosphoethanolamine/cholesterol/metal cation systems. Chem. Phys. Lipids 2006, 144, 127-136. [CrossRef] [PubMed]

18. Miñones, J.; Pais, S.; Miñones, J.; Conde, O.; Dynarowicz-Łatka, P. Interactions between membrane sterols and phospholipids in model mammalian and fungi cellular membranes-A Langmuir monolayer study. Biophys. Chem. 2009, 140, 69-77. [CrossRef]

19. Sabatini, K.; Mattila, J.-P.; Kinnunen, P.K.J. Interfacial behavior of cholesterol, ergosterol, and lanosterol in mixtures with DPPC and DMPC. Biophys. J. 2008, 95, 2340-2355. [CrossRef] [PubMed]

20. Savva, M.; Acheampong, S. The interaction energies of cholesterol and 1,2-dioleoyl-sn-glycero-3-phosphoethanolamine in spread mixed monolayers at the air-water interface. J. Phys. Chem. B 2009, 113, 9811-9820. [CrossRef]

21. Zulueta Díaz, Y.D.L.M.; Mottola, M.; Vico, R.V.; Wilke, N.; Fanani, M.L. The rheological properties of lipid monolayers modulate the incorporation of I-ascorbic acid alkyl esters. Langmuir 2016, 32, 587-595. [CrossRef]

22. Janicka, K.; Jastrzebska, I.; Petelska, A.D. Complex formation equilibria between cholesterol and diosgenin analogues in monolayers determined by the Langmuir method. Biointerphases 2018, 13, 061001. [CrossRef]

23. Del Castillo-Santaella, T.; Maldonado-Valderrama, J.; Faraudo, J.; Martín-Molina, A. Specific ion effects in cholesterol monolayers. Materials 2016, 9, 340. [CrossRef]

24. Gupta, R.K.; Suresh, K.A. AFM studies on Langmuir-Blodgett films of cholesterol. Eur. Phys. J. E 2004, 14, 35-42. [CrossRef] [PubMed]

25. Cadena-Nava, R.D.; Martin-Mirones, J.M.; Vázquez-Martínez, E.A.; Roca, J.A.; Ruiz-García, J. Direct observations of phase changes in Langmuir films of Cholesterol. Mexicana de Física 2006, 52, 32-40.

26. Hąc-Wydro, K.; Węder, K.; Mach, M.; Flasiński, M.; Wydro, P. The influence of cholesterol precursor-desmosterol-On artificial lipid membranes. Biochim. Biophys. Acta Biomembr. 2015, 1848, 1639-1645. [CrossRef] [PubMed] 
27. Wydro, P. Sphingomyelin/phosphatidylcholine/cholesterol monolayers-Analysis of the interactions in model membranes and Brewster Angle Microscopy experiments. Colloids Surf. B Biointerfaces 2012, 93, 174-179. [CrossRef] [PubMed]

28. Daear, W.; Mahadeo, M.; Prenner, E.J. Applications of Brewster angle microscopy from biological materials to biological systems. Biochim. Biophys. Acta Biomembr. 2017, 1859, 1749-1766. [CrossRef] [PubMed]

29. Hac-Wydro, K.; Dynarowicz-Latka, P. Biomedical applications of the Langmuir monolayer technique. Ann. UMCS Chem. 2008, 63, 47-60. [CrossRef]

30. Lopez, C.; Cheng, K.; Perez, J. Thermotropic phase behavior of milk sphingomyelin and role of cholesterol in the formation of the liquid ordered phase examined using SR-XRD and DSC. Chem. Phys. Lipids 2018, 215, 46-55. [CrossRef]

31. Cheng, K.; Ropers, M.-H.; Lopez, C. The miscibility of milk sphingomyelin and cholesterol is affected by temperature and surface pressure in mixed Langmuir monolayers. Food Chem. 2017, 224, 114-123. [CrossRef]

32. Murthy, A.V.R.; Guyomarc'h, F.; Lopez, C. Cholesterol decreases the size and the mechanical resistance to rupture of sphingomyelin rich domains, in lipid bilayers studied as a model of the milk fat globule membrane. Langmuir 2016, 32, 6757-6765. [CrossRef]

33. Murthy, A.V.R.; Guyomarc'h, F.; Paboeuf, G.; Vié, V.; Lopez, C. Cholesterol strongly affects the organization of lipid monolayers studied as models of the milk fat globule membrane: Condensing effect and change in the lipid domain morphology. Biochim. Biophys. Acta Biomembr. 2015, 1848, 2308-2316. [CrossRef]

34. Wydro, P.; Flasiński, M.; Broniatowski, M. Does cholesterol preferentially pack in lipid domains with saturated sphingomyelin over phosphatidylcholine? A comprehensive monolayer study combined with grazing incidence X-ray diffraction and Brewster angle microscopy experiments. J. Colloid Interface Sci. 2013, 397, 122-130. [CrossRef] [PubMed]

35. Mills, T.T.; Huang, J.; Feigenson, G.W.; Nagle, J.F. Effects of cholesterol and unsaturated DOPC lipid on chain packing of saturated gel-phase DPPC bilayers. Gen. Physiol. Biophys. 2009, 28, 126-139. [CrossRef] [PubMed]

36. Wydro, P. The interactions between cholesterol and phospholipids located in the inner leaflet of humane erythrocytes membrane (DPPE and DPPS) in binary and ternary films-The effect of sodium and calcium ions. Colloids Surf. B Biointerfaces 2011, 82, 209-216. [CrossRef] [PubMed]

37. Roldán-Vargas, S.; Martín-Molina, A.; Quesada-Pérez, M.; Barnadas-Rodríguez, R.; Estelrich, J.; Callejas-Fernández, J. Aggregation of liposomes induced by calcium: A structural and kinetic study. Phys. Rev. E 2007, 75, 021912. [CrossRef] [PubMed]

38. Roldán-Vargas, S.; Barnadas-Rodríguez, R.; Martín-Molina, A.; Quesada-Pérez, M.; Estelrich, J.; Callejas-Fernández, J. Growth of lipid vesicle structures: from surface fractals to mass fractals. Phys. Rev. E 2008, 78, 10902. [CrossRef] [PubMed]

39. Martín-Molina, A.; Rodríguez-Beas, C.; Faraudo, J. Charge reversal in anionic liposomes: Experimental demonstration and molecular origin. Phys. Rev. Lett. 2010, 104, 3-6. [CrossRef] [PubMed]

40. Wilke, N.; Maggio, B. Electrostatic field effects on membrane domain segregation and on lateral diffusion. Biophys. Rev. 2011, 3, 185-192. [CrossRef] [PubMed]

41. Martín-Molina, A.; Rodríguez-Beas, C.; Faraudo, J. Effect of calcium and magnesium on phosphatidylserine membranes: experiments and all-atomic simulations. Biophys. J. 2012, 102, 2095-2103. [CrossRef]

42. Stolarczyk, U.E.; Sidoryk, K.; Cybulski, M.; Kubiszewski, M.; Stolarczyk, K. Design of therapeutic self-assembled monolayers of thiolated abiraterone. Nanomaterials 2018, 8, 1018. [CrossRef]

43. Martín-Molina, A.; Lue, L.; Quesada-Pérez, M.; Bohinc, K. Interaction between charged lipid vesicles and point- or rod-like trivalent ions. Colloids Surf. B Biointerfaces 2019, 178, 525-529. [CrossRef]

44. Vashchenko, O.V.; Kasian, N.A.; Budianska, L.V.; Brodskii, R.Y.; Bespalova, I.I.; Lisetski, L.N. Adsorption of ions on model phospholipid membranes. J. Mol. Liq. 2019, 275, 173-177. [CrossRef]

45. Kunz, W. Specific ion effects in colloidal and biological systems. Curr. Opin. Colloid Interface Sci. 2010, 15, 34-39. [CrossRef]

46. Luque-Caballero, G.; Maldonado-Valderrama, J.; Quesada-Pérez, M.; Martín-Molina, A. Interaction of DNA with likely-charged lipid monolayers: An experimental study. Colloids Surf. B Biointerfaces 2019, 178, 170-176. [CrossRef] [PubMed]

47. Pan, J.; Tristram-Nagle, S.; Nagle, J.F. Effect of cholesterol on structural and mechanical properties of membranes depends on lipid chain saturation. Phys. Rev. E 2009, 80, 21931. [CrossRef] [PubMed] 
48. Ross, M.; Steinem, C.; Galla, H.-J.; Janshoff, A. Visualization of chemical and physical properties of calcium-induced domains in DPPC/DPPS Langmuir-Blodgett layers. Langmuir 2001, 17, 2437-2445. [CrossRef]

49. Luque-Caballero, G.; Martín-Molina, A.; Sánchez-Treviño, A.Y.; Rodríguez-Valverde, M.A.; Cabrerizo-Vílchez, M.A.; Maldonado-Valderrama, J. Using AFM to probe the complexation of DNA with anionic lipids mediated by $\mathrm{Ca}^{2+}$ : The role of surface pressure. Soft Matter 2014, 10, 2805-2815. [CrossRef] [PubMed]

50. Luque-Caballero, G.; Maldonado-Valderrama, J.; Quesada-Pérez, M.; Martín-Molina, A. Atomic force microscopy as a tool to study the adsorption of DNA onto lipid interfaces. Microsc. Res. Tech. 2017, 80, 11-17. [CrossRef] [PubMed]

51. Boettcher, J.M.; Davis-Harrison, R.L.; Clay, M.C.; Nieuwkoop, A.J.; Ohkubo, Y.Z.; Tajkhorshid, E.; Morrissey, J.H.; Rienstra, C.M. Atomic view of calcium-induced clustering of phosphatidylserine in mixed lipid bilayers. Biochemistry 2011, 50, 2264-2273. [CrossRef] [PubMed]

52. Lehrmann, R.; Seelig, J. Adsorption of $\mathrm{Ca}^{2+}$ and $\mathrm{La}^{3+}$ to bilayer-membranes-Measurement of the adsorption enthalpy and binding constant with titration calorimetry. Biochim. Biophys. Acta Biomembr. 1994, 1189, 89-95. [CrossRef]

53. Pandit, S.A.; Chiu, S.-W.; Jakobsson, E.; Grama, A.; Scott, H.L. Cholesterol packing around lipids with saturated and unsaturated chains: A simulation study. Langmuir 2008, 24, 6858-6865. [CrossRef]

54. Kučerka, N.; Perlmutter, J.D.; Pan, J.; Tristram-Nagle, S.; Katsaras, J.; Sachs, J.N. The effect of cholesterol on short- and long-chain monounsaturated lipid bilayers as determined by molecular dynamics simulations and X-ray scattering. Biophys. J. 2008, 95, 2792-2805. [CrossRef] [PubMed]

55. Ermilova, I.; Lyubartsev, A.P. Cholesterol in phospholipid bilayers: Positions and orientations inside membranes with different unsaturation degrees. Soft Matter 2019, 15, 78-93. [CrossRef] [PubMed]

56. Himeno, H.; Shimokawa, N.; Komura, S.; Andelman, D.; Hamada, T.; Takagi, M. Charge-induced phase separation in lipid membranes. Soft Matter 2014, 10, 7959-7967. [CrossRef] [PubMed]

57. Casper, C.B.; Verreault, D.; Adams, E.M.; Hua, W.; Allen, H.C. Surface potential of DPPC monolayers on concentrated aqueous salt solutions. J. Phys. Chem. B 2016, 120, 2043-2052. [CrossRef] [PubMed]

58. Schultz, Z.D.; Pazos, I.M.; McNeil-Watson, F.K.; Lewis, E.N.; Levin, I.W. Magnesium-induced lipid bilayer microdomain reorganizations: Implications for membrane fusion. J. Phys. Chem. B 2009, 113, 9932-9941. [CrossRef] [PubMed]

59. Stamatatos, L.; Silvius, J.R. Effects of cholesterol on the divalent cation-mediated interactions of vesicles containing amino and choline phospholipids. Biochim. Biophys. Acta Biomembr. 1987, 905, 81-90. [CrossRef] 